\title{
Evaluasi Pengembangan Wilayah Permukiman Berdasarkan Pemetaan Kerusakan Permukiman Akibat Banjir Lahar di Kali Putih, Kabupaten Magelang
}

\author{
Settlement Development Evaluation Based On The Mapping Of \\ Damage Settlement Due To Lahar Flood In Kali Putih, Magelang
}

\author{
Rosalina Kumalawati ${ }^{1}$, Seftiawan Samsu Rijal, Rijanta, Junun Sartohadi, Rimawan \\ Pradiptyo $^{2}$
}

\begin{abstract}
Abstrak: Penelitian ini bertujuan untuk (1) melakukan penilaian tingkat kerusakan permukiman yang terkena banjir lahar, (2) menganalisis tingkat kerusakan permukiman akibat banjir lahar di daerah penelitian dan (3) menganalisis pengalokasian ruang pembangunan pemukiman berbasis tingkat kerusakan permukiman pasca banjir lahar. Metode yang digunakan adalah GPS Tracking untuk mengetahui luapan banjir lahar, klasifikasi tingkat kerusakan permukiman berdasar kriteria yang telah ditetapkan. Spatial autocorrelation untuk mengetahui pola kerusakan permukiman. Hasil penelitian menunjukkan bahwa kerusakan bangunan permukiman akibat banjir lahar tidak hanya disebabkan oleh jarak rumah terhadap sungai tetapi disebabkan oleh material bangunan permukiman tersebut. Pola spasial yang dihasilkan adalah 0,68 (mengelompok) untuk Roboh/Hanyut, 0,62 (mengelompok) untuk Rusak Berat, 1,05 (mengelompok) untuk Rusak Ringan, 0,64 (mengelompok) untuk Rusak Sedang, dan 1,21 (mengelompok) untuk Tidak Rusak.
\end{abstract}

\section{Kata Kunci : erupsi, banjir lahar, kerusakan permukiman}

\begin{abstract}
The aim of this study are (1) to assess the damage of settlement due to lahar flood in study area, (2) to analyze the damage of settlement and (3) to analyze the allocated space of settlement development based on classification of damage settlement. Methods that used in this study are GPS Tracking to know the distribution of lahar flood, classification of damage settlement based on predetermined criteria and spatial autocorrelation to know the pattern of damage settlement. The result of this study is showing that damage settlement due to lahar flood is not only caused by the house distance to the river but also by the materials of it. The spatial pattern of damage settlement is 0,68 (clustered) for Collapse, 0,62 (clustered) for High Damaged, 1,05 (clustered) for Low Damaged, 0,64 (clustered) for Medium Damaged) and 1,21 (clustered) for No Damaged.
\end{abstract}

Keywords : eruption, lahar flood, damage settlement

\footnotetext{
${ }^{1}$ Fakultas Geografi, Universitas Gadjah Mada

${ }^{2}$ Fakultas Ekonomika dan Bisnis, Universitas Gadjah Mada

Sekip Utara Jalan Kaliurang, Bulaksumur, Yogyakarta, 55281
} 


\section{Pendahuluan}

Negara Indonesia memiliki gunungapi yang terbanyak di dunia, yaitu 129 gunungapi aktif atau sekitar $15 \%$ dari seluruh gunungapi yang ada. Lingkup studi mengenai gunungapi meliputi petrologi, mitigasi dan evaluasi bencana, survey pemetaan geologi, pemantauan atau mitigasi erupsi, tata guna lahan, pertanian dan eksplorasi sumber daya alam. Gunungapi bisa merupakan rangkaian pegunungan, tetapi sangat berbeda dengan gunung lainnya. Gunungapi tidaklah dibentuk oleh perlipatan, erosi ataupun pengangkatan, tetapi membentuk tubuhnya sendiri oleh adanya pengumpulan bahan erupsinya, seperti lava, batuan dan aliran piroklastik (Sumintadiredja, 2000).

Gunungapi di Indonesia yang berada dalam keadaan sangat potensial untuk meletus sekitar 10 hingga 15 gunungapi. Salah satu gunungapi yang aktif di Indonesia adalah Gunungapi Merapi. Gunungapi ini terletak di perbatasan Provinsi Daerah Istimewa Yogyakarta dan Provinsi Jawa Tengah. Adapun secara geografis, Gunungapi Merapi terletak pada posisi $7^{0} 32.5^{\prime}$ Lintang Selatan dan $110^{\circ} 26.5^{\prime}$ Bujur Timur, dengan ketinggian $2980 \mathrm{~m}$ dpl. Bentuk ancaman dari bencana alam ini berupa korban jiwa dan kerusakan pemukiman/harta/benda akibat aliran lava, lemparan abu, awan panas, gas beracun, dan lain lain.

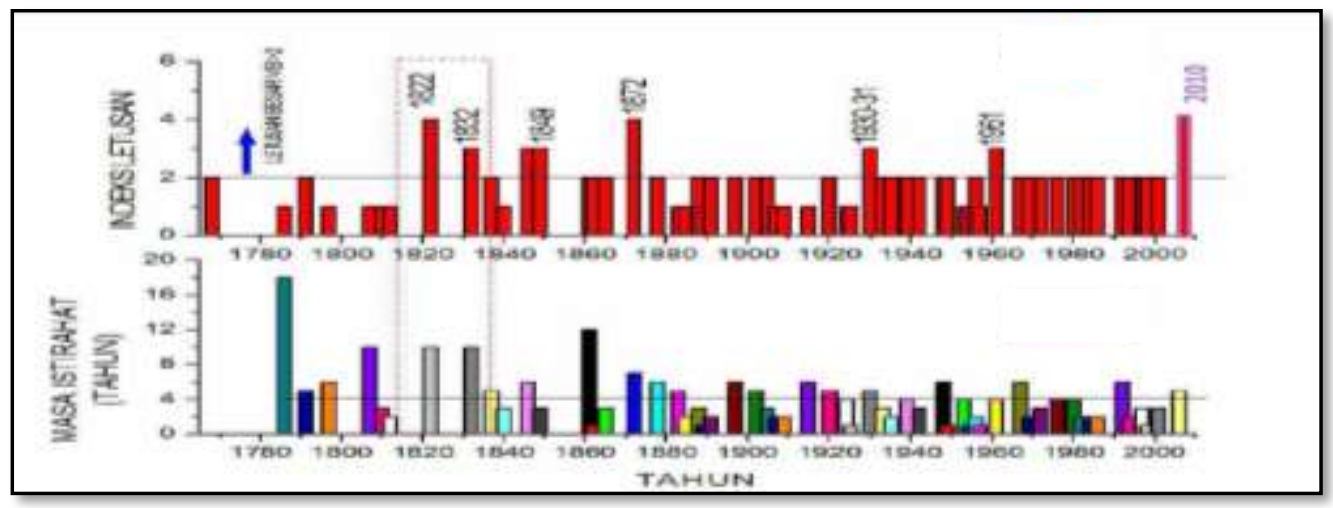

Sumber: Cholik, 2011

Gambar 1. Indeks letusan dan masa istirahat Gunungapi Merapi

Cholik (2011) menyebutkan bahwa Gunungapi Merapi telah mengalami 5 perkembangan masa kejadian sebagai berikut.

- Pra Merapi, ditandai dengan balastik andesit, tidak mengandung orthopiroxe, berumur 700.000 tahun yang lalu.

- Merapi Tua berumur 60.000 hingga 8.000 tahun yang lalu, ditandai dengan lava balastik dengan produk erupsi berupa andesit balastik dan awan panas.

- Merapi Muda, berumur 2.000 hingga 8.000 tahun yang lalu, ditandai dengan lava andesit, produk erupsi berupa aliran lava dan awan panas dengan letusan bersifat efusif, eksplosif, debris avalanche, membentuk Kawah Pasar Bubar (2 km x $7 \mathrm{~km})$, dan indeks kualitas letusan bernilai $>4$.

- Merapi Baru berumur 1.600 hingga 2.000 tahun yang lalu, ditandai dengan aliran lava basalt dan lava andes, mampu membentuk kubah, produk erupsi berupa awan panas dengan indeks kualitas letusan bernilai $<3$.

- Merapi Terkini, ditandai dengan kubah lava dan awan panas tipe Merapi. Sejarah letusan Gunungapi Merapi diketahui telah terjadi sejak tahun 1780. Gunungapi Merapi 
meletus terakhir kali pada tahun 2010 dengan volume letusan $140 \mathrm{Juta}^{3}$, dengan indeks kualitas letusan bernilai 4 atau setara dengan letusan yang pernah terjadi pada tahun 1822.

Tanggal 26 Oktober 2010 Gunungapi Merapi mengalami delapan kali letusan yang menghasilkan awan panas (nuee ardente) dan material piroklastik. Tanggal 4 November 2010, aliran material piroklastik berjumlah 30 kali lipat dari erupsi tahun 2006 yang hanya sebesar 5 juta $\mathrm{m}^{3}$, mencapai jarak $15 \mathrm{~km}$ dari puncak yang menghilangkan 135 jiwa. Bahaya primer akibat erupsi 2010 sudah sangat kecil, potensi bahaya sekunder masih terus mengancam sampai lima tahun ke depan bahkan lebih, tidak hanya di wilayah lereng Merapi tetapi juga wilayah bawah khususnya daerah perkotaan yang padat permukiman (Hadmoko et al, 2011). Perbandingan letusan Merapi tahun 1780 hingga 2010 pada Gambar 1.

Banjir lahar merupakan salah satu jenis bahaya sekunder yang diakibatkan oleh erupsi Gunungapi Merapi. Tercatat sejak tahun 1822 hingga 2010, Lavigne (2000) menyatakan bahwa banjir lahar yang berasal dari erupsi Gunungapi Merapi mengalir melalui sungai-sungai yang berhulu di Gunungapi Merapi, antara lain Kali Trinsing, Kali Senowo, Kali Pabelan, Kali Putih, Kali Bebeng, Kali Batang, Kali Lamat, Kali Blongkeng. Sungai-sungai tersebut terletak di lereng barat Gunungapi Merapi. Tahun 2010, Kali Putih termasuk sungai yang paling banyak dialiri banjir lahar akibat erupsi Gunungapi Merapi, melimpas dan mengakibatkan kerusakan permukiman di Kecamatan Salam dan Ngluwar (Tabel 1).

Tabel 1. Daftar Rumah dan Jumlah Pengungsi yang Terkena Banjir Lahar Pasca Erupsi Gunungapi Merapi 2010

\begin{tabular}{lllllll}
\hline \multirow{2}{*}{ Kecamatan } & Desa & $\begin{array}{l}\text { Rumah } \\
\text { Roboh } \\
\text { Hanyut }\end{array}$ & $\begin{array}{l}\text { Rusak } \\
\text { Berat }\end{array}$ & $\begin{array}{l}\text { Rusak } \\
\text { Sedang }\end{array}$ & $\begin{array}{l}\text { Rusak } \\
\text { Ringan }\end{array}$ & Pengungsi \\
\hline \multirow{4}{*}{ Salam } & Gulon & - & 4 & - & - & 1.005 \\
& Sucen & - & 4 & - & - & 1 \\
& Jumoyo & 54 & 36 & 5 & - & 1.005 \\
& Seloboro & - & 2 & 7 & 2 & 68 \\
Ngluwar & Sirahan & 11 & 58 & - & - & - \\
Jumlah & Blongkeng & - & 6 & - & - & - \\
\hline
\end{tabular}

Sumber : Badan Nasional Penanggulangan Bencana (2011)

Penyajian kerusakan permukiman dalam peta menjadi salah satu kompetensi pada bidang ilmu geografi. Pemetaan kerusakan permukiman akibat banjir lahar telah dilakukan oleh BNPB (Badan Nasional Penanggulangan Bencana) pada tahun 2011 dengan skala 1 : 100.000. Pada skala tersebut, tidak dimungkinkan untuk memperoleh informasi kerusakan dari masing - masing rumah. Data penginderaan jauh berupa citra IKONOS mampu melakukan pemetaan skala tinggi. Citra IKONOS tahun 2010 dengan resolusi spasial $4 \mathrm{~m}$ pada multispektral dapat melakukan pemetaan $1: 8.000$. (Tobler, 1987).

Berdasarkan latar belakang yang telah disampaikan di atas dan juga dengan memperhatikan kemampuan Penginderaan Jauh dan Sistem Informasi Geografis dalam menampilkan kedetailan pemetaan, maka penelitian ini mengambil judul : Evaluasi Pengembangan Pemukiman Berdasarkan Pemetaan Kerusakan Permukiman Akibat Banjir Lahar Pasca Erupsi Gunungapi Merapi 2010 di Kali Putih Kabupaten Magelang. Penelitian ini ditujukan untuk melakukan analisis kerusakan permukiman akibat banjir lahar dengan mengambil wilayah penelitian di Kecamatan Salam dan Ngluwar, sebagai kecamatan yang terkena banjir lahar terparah dari Kali Putih. 


\section{Tujuan Penelitian}

1. Melakukan penilaian tingkat kerusakan permukiman yang terkena banjir lahar di daerah penelitian,

2. Menganalisis tingkat kerusakan permukiman akibat banjir lahar di daerah penelitian dan,

3. Menganalisis pengalokasian ruang pembangunan pemukiman berbasis tingkat kerusakan permukiman pasca banjir lahar.

\section{Metode Penelitian}

Metode pengambilan sampel dengan menggunakan stratified random sampling. Mustafa (2000) menyatakan terdapat beberapa prosedur dalam penentuan sampel menggunakan metode ini, yakni 1) menyiapkan sampling frame, 2) membagi sampling frame tersebut berdasarkan strata yang dikehendaki, 3) menentukan jumlah sampel dalam setiap stratum, 4) memilih sampel dari setiap stratum secara acak. Sampling frame yang digunakan adalah endapan banjir lahar, Sampling frame dibagi ke dalam beberapa strata sesuai dengan tebal endapan banjir lahar. Sampel di-plot dengan menggunakan GPS. Hasil ploting akan dimasukkan ke dalam peta untuk mengetahui posisi rumah.

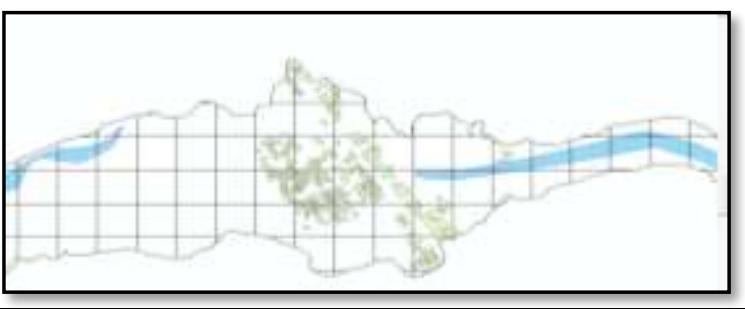

\section{Gambar 1. Membuat Grid Pada Luapan Banjir Lahar Hasil Tracking}

Kondisi bangunan pra banjir lahar dapat diketahui dengan cara wawancara dengan daftar pertanyaan kepada penduduk yang terkena banjir lahar atau kepada perangkat desa yang wilayahnya terkena banjir lahar. Pengukuran luapan banjir lahar dilakukan dengan gps tracking. GPS tracking hanya dilakukan di area desa yang terkena banjir lahar sesuai dengan data desa terkena banjir lahar BNPB pada Tabel 1.1. Hasil GPS tracking harus diubah ke dalam struktur data polygon dengan di dijitasi agar dapat diketahui luasan dan cakupan dari banjir lahar. Keterangan lebih lanjut mengenai teknik pengambilan sampel dapat dilihat pada Gambar 1; Gambar.2; Gambar 3; Gambar 4; dan Gambar 5.

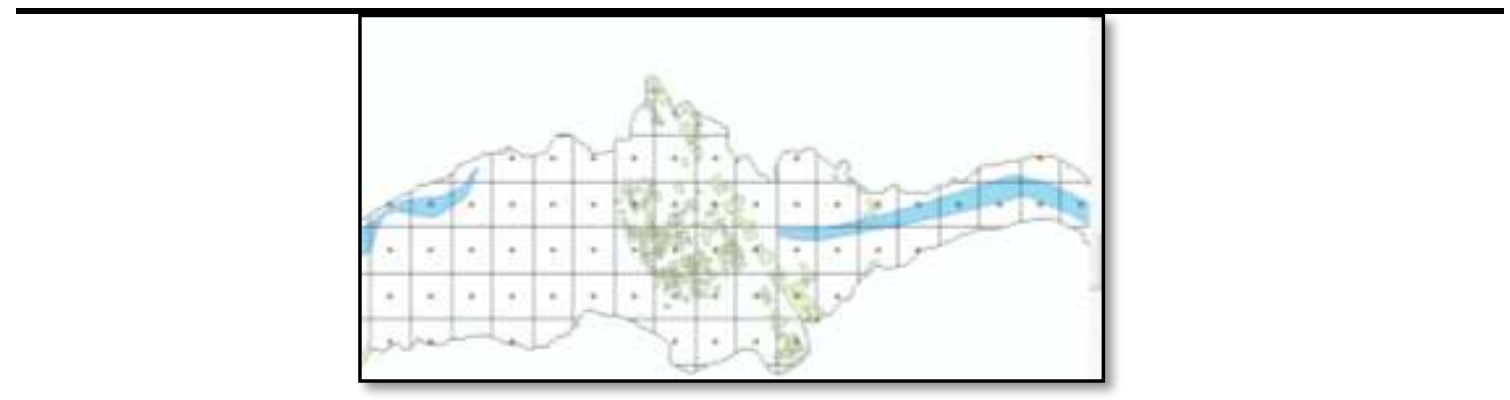

Gambar 2. Menentukan Titik Untuk Pengambilan Sampel Ketinggian Banjir Lahar 


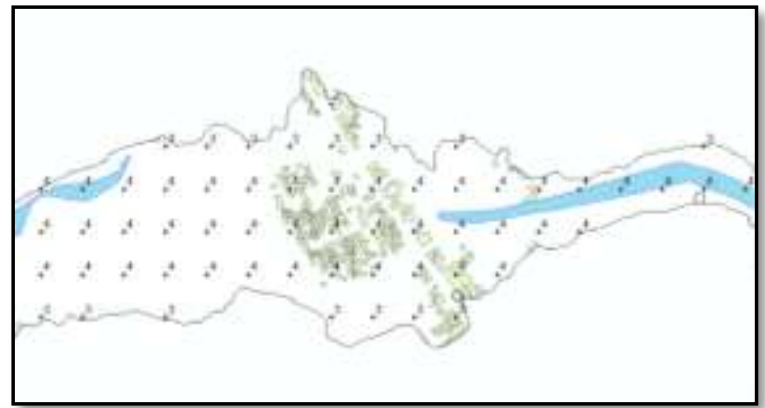

Gambar 3. Menampilkan Ketinggian Endapan Banjir Lahar

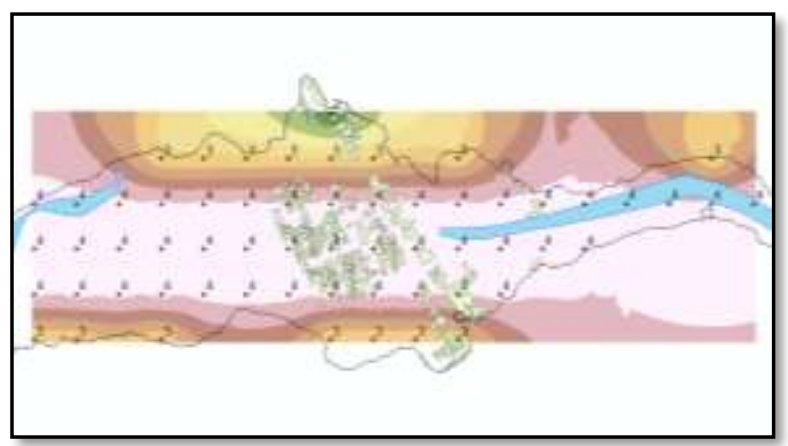

Gambar 4. Melakukan Interpolasi Ketinggian Endapan Banjir Lahar

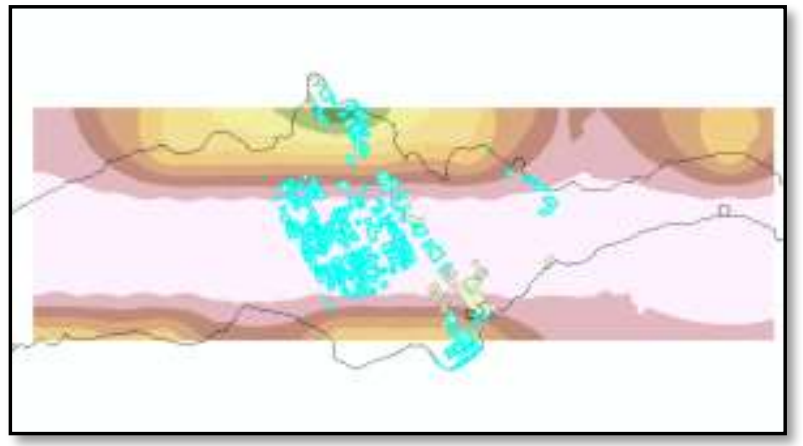

Gambar 5. Sampel Rumah Yang Disurvey Sesuai Ketinggian Endapan Banjir Lahar

Analisis data meliputi teknik interpretasi citra guna mengetahui objek yang akan dijadikan sampel, kemudian penentuan parameter guna melakukan penilaian tingkat kerusakan permukiman, dan analisis pola spasial untuk mendeskripsikan sebaran kerusakan permukiman. Penjelasan masing-masing analisis adalah : 


\section{Penilaian Tingkat Kerusakan Permukiman Akibat Banjir Lahar}

\section{a. Interpretasi Citra}

Interpretasi citra adalah kegiatan untuk melakukan penggalian informasi dari citra. Penggalian informasi pada citra dilakukan berdasarkan resolusi spasial citra. Citra memiliki tiga jenis resolusi spasial, yakni tinggi, menengah dan rendah. Citra dengan resolusi spasial tinggi contohnya IKONOS dan Quickbird. Citra dengan resolusi spasial yang menengah adalah Landsat dan ASTER. Citra dengan resolusi spasial yang rendah adalah NOAA dan GOES. Peneliti menggunakan citra IKONOS, karena memiliki resolusi spasial 1 meter pada pankromatik dan 4 meter pada multispektral. Kusumowidagdo et al (2007) menyatakan terdapat delapan unsur interpretasi, adalah :

- Rona/Warna adalah tingkat kegelapan/kecerahan obyek pada citra, rona merupakan tingkatan dari hitam ke putih atau sebaliknya. Warna adalah wujud yang tampak pada mata, menunjukkan tingkat kegelapan yang beragam.

- Bentuk adalah variabel kualitatif yang memberikan kerangka suatu obyek. Bentuk dapat berupa yang tampak dari luar (umum), maupun menyangkut susunan atau struktur yang lebih rinci.

- Bayangan adalah obyek atau gejala yang terletak di daerah sebelah jatuh sinar. Bayangan umumnya tampak samar atau bahkan tidak tampak.

- Ukuran adalah atribut obyek yang berupa jarak, luas, tinggi dan volume.

- Tekstur biasa dinyatakan dalam wujud kasar, halus, atau bercak-bercak. Tekstur juga dianggap sebagai tingkat kekasaran suatu obyek.

- Pola merupakan ciri yang menandai bagi banyak obyek buatan manusia dan beberapa obyek alamiah yang membentuk susunan keruangan.

- Situs merupakan hasil pengamatan dari hubungan antar obyek di lingkungan sekitarnya atau letak suatu obyek terhadap obyek lain, jadi bukan mencirikan suatu obyek secara langsung.

- Asosiasi adalah keterkaitan antara obyek yang satu dengan yang lain, berdasarkan asosiasi tersebut maka bila telah dikenali satu obyek tertentu maka dapat dijadikan petunjuk bagi obyek yang lain.

Citra IKONOS dimanfaatkan untuk melakukan interpretasi persil bangunan. Peneliti menggunakan bentuk, ukuran, pola, bayangan dan situs sebagai kunci interpretasi persil bangunan (Tabel 2).

\section{Tabel 2 Kunci Interpretasi}

\begin{tabular}{lllllllll}
\hline \multirow{2}{*}{ Objek } & \multirow{2}{*}{ Rona } & Bentuk & Bayangan & Ukuran & Tekstur & Pola & Situs & Asosiasi \\
\hline Bangunan & $\mathrm{v}$ & $\mathrm{v}$ & $\mathrm{v}$ & & $\mathrm{v}$ & $\mathrm{v}$ \\
\hline
\end{tabular}

Sumber : Peneliti, 2012

\section{b. Parameter Penilaian Tingkat Kerusakan Bangunan}

Kerusakan bangunan dinilai menggunakan kriteria kerusakan bangunan. Hasil penilaian disajikan dalam bentuk tabel dan peta sebaran kerusakan permukiman. Kriteria kerusakan bangunan akibat banjir lahar (Tabel 3). 
Tabel 3. Kriteria Kerusakan Bangunan Akibat Banjir Lahar

\begin{tabular}{|c|c|c|c|}
\hline No & $\begin{array}{l}\text { Kategori } \\
\text { Kerusakan }\end{array}$ & Kriteria Kerusakan & Uraian \\
\hline 1. & $\begin{array}{l}\text { Hanyut } \\
\text { Roboh }\end{array}$ & $\begin{array}{l}\text { Bangunan hanyut terbawa } \\
\text { banjir lahar, bangunan roboh, } \\
\text { total bangunan tertimbun lahar } \\
\text { atau sebagian besar komponen } \\
\text { struktur rusak }\end{array}$ & $\begin{array}{l}\text { - } \quad \text { Bangunan hilang atau roboh total } \\
\text { - } \quad \text { Bangunan terkubur endapan lahar lebih dari 50\% } \\
\text { - } \quad \text { Sebian bangunan hilang sebesar } 50 \% \text { atau lebih } \\
\text { - } \quad \text { Sebagian besar kolom, balok, dan atau atap rusak } \\
\text { - } \quad \text { Instalasi listrik rusak total } \\
\text { - } \quad \text { Pintu/jendela/kusen hilang/rusak total }\end{array}$ \\
\hline 2. & Rusak Berat & 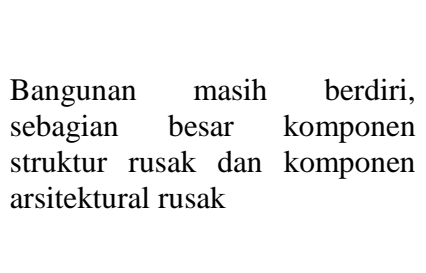 & $\begin{array}{ll}\text { - } & \text { Bangunan masih berdiri } \\
\text { - } & \text { Bangunan tertimbun endapan lahar } 50 \% \\
\text { - } & \text { Sebagian rangka atap patah } \\
\text { - } & \text { Sebagian dinding dan atau atap roboh/rusak } \\
\text { - } & \text { Sebagian instalasi listrik rusak/terputus } \\
\text { - } & \text { Pintu/jendela/kusen rusak parah }\end{array}$ \\
\hline 3. & Rusak Sedang & $\begin{array}{lrr}\text { Bangunan masih } & \text { berdiri, } \\
\text { sebagian kecil komponen } \\
\text { struktur rusak dan } & \text { komponen } \\
\text { arsitektural rusak } & \end{array}$ & $\begin{array}{l}\text { - } \quad \text { Bangunan masih berdiri } \\
\text { - } \quad \text { Bangunan tertimbun lahar } 30 \% \\
\text { - } \quad \text { Retak-retak pada dinding dan atau atap } \\
\text { - } \quad \text { Pintalasi listrik rusak sebagian } \\
\quad \text { inda/kusen rusak sebagian }\end{array}$ \\
\hline 4. & Rusak Ringan & $\begin{array}{l}\text { Bangunan masih berdiri, tidak } \\
\text { ada kerusakan struktur, hanya } \\
\text { terdapat kerusakan komponen } \\
\text { arsitektural }\end{array}$ & $\begin{array}{ll}\text { - } & \text { Bangunan masih berdiri } \\
\text { - } & \text { Bangunan tergenang lahar }<30 \% \\
\text { - } & \text { Pintu/jendela/kusen perlu diperbaiki } \\
\text { - } & \text { Instalasi listrik tidak rusak } \\
\text { - } & \text { Dinding perlu di cat kembali }\end{array}$ \\
\hline 5. & Tidak Rusak & $\begin{array}{l}\text { Bangunan utuh, tidak ada } \\
\text { kerusakan struktur, hanya } \\
\text { terkena genangan lahar di teras } \\
\text { rumah }\end{array}$ & $\begin{array}{l}\text { - } \quad \text { Bangunan masih berdiri } \\
\text { - Tidak ada kerusakan pada pintu/jendela } \\
\text { - Terkena genangan lahar di teras kurang dari } 20 \mathrm{~cm}\end{array}$ \\
\hline
\end{tabular}

Sumber : BAKORNAS dalam Departemen Pekerjaan Umum, 2006; dan modifikasi, 2012

\section{Menganalisis Tingkat Kerusakan Permukiman Akibat Banjir Lahar di Daerah Penelitian}

\section{a. Analisis Pola Spasial Kerusakan Permukiman}

Yunus (2010) menyatakan bahwa terdapat 9 analisis keruangan, yaitu : analisis pola keruangan, struktur keruangan, proses keruangan, interaksi keruangan, organisasi keruangan, asosiasi keruangan, komparasi keruangan, kecenderungan keruangan, dan sinergisme keruangan. Penelitian ini menggunakan analisis pola keruangan (spatial pattern analyze). Langkah-langkah untuk melakukan analisis pola spasial menurut Yunus (2010) adalah :

\section{1). Mengabstraksikan objek kajian}

Peneliti mengabstraksikan kenampakan di muka bumi yang diinterpretasi melalui citra. Skala pemetaan yang digunakan adalah skala besar, sehingga kenampakan rumah ditampilkan sebagai poligon, sungai sebagai poligon dan garis, penutup serta penggunaan lahan sebagai poligon. 


\section{2). Mengklasifikasikan sebaran}

Peneliti melakukan identifikasi kekhasan sebaran objek kajian. Penelitian ini akan melakukan identifikasi pada kekhasan sebaran kerusakan permukiman yang terkena banjir lahar. Hal ini dilakukan untuk mengetahui cerminan pola sebaran seperti mempola (patterned distribution) atau tidak berpola (unpatterned distribution). Dan untuk mengetahui spesifikasi sebaran, misalnya mengelompok (clustered) atau acak (random).

\section{3). Menjawab pertanyaan geografi yang berupa 5W 1H (What, Who, When, Where, Why, How)}

Peneliti berupaya melakukan penyimpulan dari penelitian dengan menjawab pertanyaan geografi yang berupa $5 \mathrm{~W} 1 \mathrm{H}$. Jawaban dari penelitian ini akan ditemukan dari keterkaitan antar variabel yang diteliti yaitu luapan banjir lahar dan kerusakan permukiman.

\section{b. Menentukan Pola Spasial Kerusakan Permukiman}

Penentuan pola spasial kerusakan permukiman dapat dilakukan dengan menggunakan teknik Spatial Autocorrelation. Teknik ini adalah salah satu cara yang dapat digunakan untuk mengetahui interaksi spasial dari beberapa obyek. Spatial Autocorrelation terdapat pada toolbox software ArcGIS 9.3.

Teknik Spatial Autocorrelation memiliki beberapa ketentuan dalam melakukan perhitungan, antara lain (1) Konsep hubungan spasial yang digunakan oleh teknik ini adalah inverse distance, teknik ini akan melakukan perhitungan pola spasial berdasar jarak sebuah obyek dengan obyek yang lain (2) Metode perhitungan jarak, terdapat dua metode perhitungan jarak yang terdapat pada teknik ini yaitu Euclidean Distance dan Manhattan Distance (3)Standarisasi perhitungan, adalah pilihan yang dapat digunakan untuk menghilangkan bias perhitungan yang diakibatkan oleh desain pemilihan sampel atau skema agregasi.

Teknik Spatial Autocorrelation akan menampilkan hasil perhitungan dengan klasifikasi pola spasial mulai tersebar (dispersed) hingga mengelompok (clustered) (Gambar $6)$.

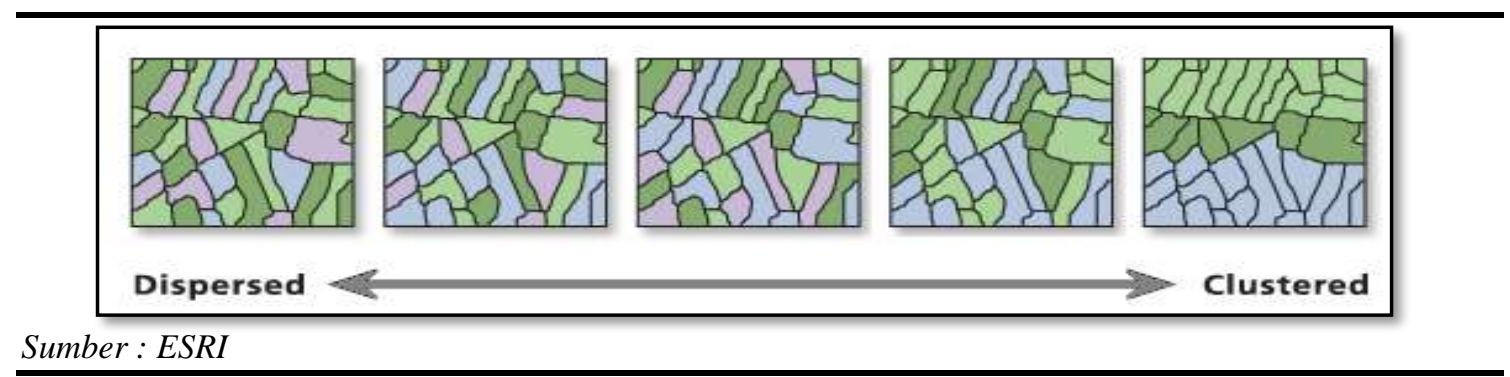

Gambar 6. Hasil klasifikasi yang akan ditampilkan Spatial Autocorrelation

\section{Menganalisis Pengalokasian Ruang Pembangunan Pemukiman berbasis Tingkat Kerusakan Permukiman Pasca Banjir Lahar}

Pemerintah daerah perlu memanfaatkan kesadaran masyarakat, setelah banjir lahar terjadi. Kondisi masyarakat sedang fokus terhadap kejadian banjir lahar, serta memikirkan cara bagaimana agar banjir lahar yang telah terjadi, tidak menimbulkan suatu bencana yang baru. Cara yang dapat dilakukan yaitu dengan menyesuaikan RTRW (Rencana Tata Ruang Wilayah) yang ada, dan menambahkan aspek pengetahuan tentang bencana dalam rencana tata ruang khususnya banjir lahar. Informasi tentang bencana alam (dan juga bencana karena banjir lahar) perlu dipetakan. Pemetaan banjir lahar dilakukan untuk 
kawasan yang sudah terbangun dan yang direncanakan untuk dibangun di kemudian hari. Wilayah yang sudah terbangun, peta kerusakan permukiman pasca banjir lahar perlu dibuat untuk menunjukkan wilayah yang struktur bangunan dan prasarananya perlu diperkuat agar tahan terhadap bencana.

\section{Hasil Dan Pembahasan}

\section{Penilaian Tingkat Kerusakan Permukiman Akibat Banjir Lahar}

Penilaian tingkat kerusakan permukiman akibat banjir lahar terdiri dari dua bagian, yaitu kondisi permukiman sebelum banjir lahar 2010 dan kondisi permukiman pasca banjir lahar.

\section{a. Kondisi Permukiman Sebelum Banjir Lahar}

Parameter kondisi bangunan yang dipakai untuk analisis adalah material dinding, material lantai, jenis atap, jumlah lantai dan jarak rumah dari sungai. Untuk mengetahui kondisi permukiman sebelum banjir lahar dilakukan survey lapangan dan juga wawancara dengan penduduk setempat (Gambar 4.1). Total keseluruhan sampel yang diambil adalah 89 rumah.

Sumber: Foto Rosalina Kumalawati, dkk, 2012

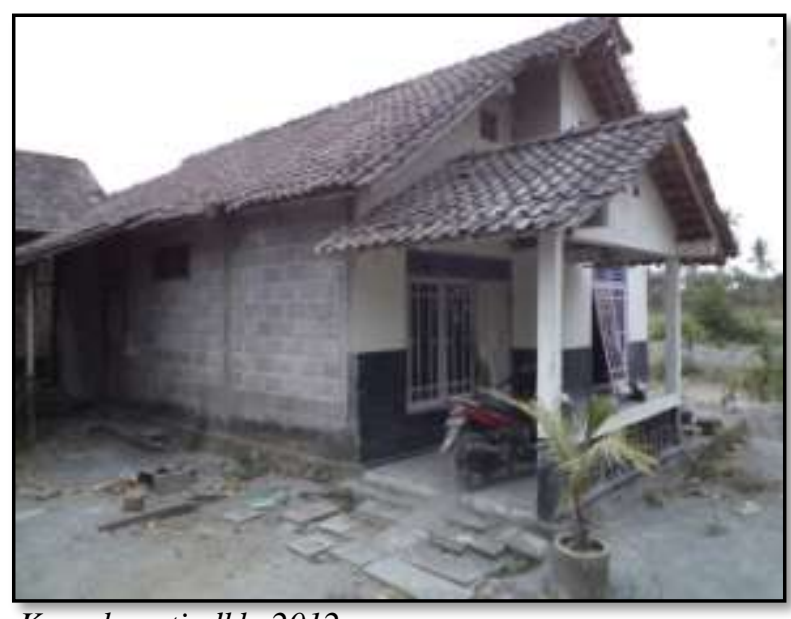

Gambar 7 Kondisi Rumah yang Tidak Terkena Banjir Lahar 2010

Tabel 4. Jumlah Sampel Rumah Berdasarkan Jarak dari Sungai

\begin{tabular}{lcc}
\hline No. & Jarak Dari Sungai $(\mathrm{m})$ & Jumlah Rumah \\
\hline 1. & $0-50$ & 42 \\
\hline 2. & $51-100$ & 30 \\
\hline 3. & $101-250$ & 17 \\
\hline & Jumlah & 89 \\
\hline
\end{tabular}

Sumber : Hasil Pengolahan dan Analisis Data Primer, 2012

Berdasarkan hasil pengolahan data diketahui bahwa rumah yang di survey didominasi oleh material bata/batako, beratap genteng, dengan lantai berupa semen dan hanya satu tingkat. Adapun mengenai jarak terhadap sungai, dikelompokkan 42 rumah 
berada jarak $0-50 \mathrm{~m}, 30$ rumah berada $51-100 \mathrm{~m}$, dan 17 rumah berjarak $101-250 \mathrm{~m}$ dari sungai (Tabel 4.1). Secara jumlah total maka dapat dipaparkan bahwa rumah dengan material dinding sebanyak 58 rumah, material semen 42 rumah, 89 rumah atau semua rumah beratap genteng dan 89 rumah berlantai 1 .

Silitonga (2010) menyebutkan bahwa rumah dengan kriteria berpondasi, dinding berupa batu bata / batako, beratap genteng dan memiliki lantai berupa plester / keramik adalah ciri rumah permanen. Temuan peneliti di lapangan, sesuai dengan kriteria yang diberikan, dengan demikian, dapat disimpulkan bahwa kondisi permukiman di daerah penelitian adalah termasuk kategori rumah permanen.

\section{b. Kondisi Permukiman Pasca Banjir Lahar}

Kondisi permukiman pasca banjir lahar dikelompokkan menjadi beberapa kelas kerusakan permukiman sesuai dengan kriteria yang telah ditetapkan. Hasil pengolahan mengenai kondisi permukiman pasca banjir lahar ditampilkan dalam Tabel 4.2. Pada Tabel 4.2 dan Gambar 4.2 dapat dilihat bahwa total keseluruhan jumlah rumah yang terkena banjir lahar adalah 1.290 rumah. Kelas kerusakan permukiman didominasi oleh Roboh/Hanyut sebanyak 814 rumah, rusak berat sebanyak 71 rumah, rusak sedang sebanyak 200 rumah, rusak ringan 140 rumah, dan tidak rusak sejumlah 65 rumah.

Tabel 5. Kelas Kerusakan Permukiman Akibat Banjir Lahar

\begin{tabular}{|c|c|c|c|c|c|c|c|c|}
\hline \multirow[b]{2}{*}{ No } & \multirow[b]{2}{*}{ Kecamatan } & \multirow[b]{2}{*}{ Desa } & \multicolumn{5}{|c|}{ Kelas Kerusakan Permukiman } & \multirow{2}{*}{$\begin{array}{l}\text { Jumlah } \\
\text { Rumah }\end{array}$} \\
\hline & & & $\begin{array}{l}\text { Roboh/ } \\
\text { Hanyut }\end{array}$ & $\begin{array}{l}\text { Rusak } \\
\text { Berat }\end{array}$ & $\begin{array}{l}\text { Rusak } \\
\text { Sedang }\end{array}$ & $\begin{array}{l}\text { Rusak } \\
\text { Ringan }\end{array}$ & $\begin{array}{l}\text { Tidak } \\
\text { Rusak }\end{array}$ & \\
\hline 1 & \multirow{4}{*}{ Salam } & \multirow{4}{*}{$\begin{array}{l}\text { Jumoyo } \\
\text { Gulon } \\
\text { Seloboro } \\
\text { Sirahan }\end{array}$} & 108 & 8 & 19 & 61 & 24 & 220 \\
\hline 2 & & & 0 & 0 & 25 & 3 & 0 & 28 \\
\hline 3 & & & 97 & 15 & 5 & 1 & 1 & 119 \\
\hline 4 & & & 553 & 43 & 149 & 75 & 40 & 860 \\
\hline 5 & \multirow{2}{*}{$\begin{array}{l}\text { Ngluwar } \\
\text { h }\end{array}$} & Blongkeng & 56 & 5 & 2 & 0 & 0 & 63 \\
\hline \multicolumn{2}{|c|}{ Jumlah } & & 814 & 71 & 200 & 140 & 65 & 1290 \\
\hline
\end{tabular}

Sumber : Hasil Pengolahan dan Analisis Peta Kerusakan Permukiman Akibat Banjir Lahar, 2012

Permukiman yang paling banyak terkena dampak dari banjir lahar adalah Desa Sirahan yaitu sebanyak 860 rumah. Sedangkan desa yang paling sedikit terkena dampak dari banjir lahar adalah Desa Gulon yaitu sebanyak 7 rumah. Kerusakan permukiman terparah yang roboh/hanyut terdapat di Desa Sirahan, yakni sebanyak 553 rumah, kemudian diikuti Jumoyo sebanyak 108 rumah, Seloboro 97 rumah, dan Blongkeng 56 rumah. Kelas kerusakan yang terbanyak kedua adalah Rusak Sedang. Pada kelas kerusakan ini, Desa Sirahan masih mendominasi dengan 149 rumah, Gulon 25 rumah, Jumoyo 19 rumah, Seloboro 5 rumah, dan Blongkeng 2 rumah.

Kelas kerusakan rusak ringan hampir seluruh desa terdapat didalamnya, akan tetapi ada satu desa yang tidak termasuk yaitu Blongkeng. Desa yang terbanyak memiliki rumah dengan kelas kerusakan permukiman rusak ringan adalah Sirahan dengan 75 rumah, Jumoyo 61 rumah, Gulon 3 rumah, dan Seloboro 1 rumah. Satu desa tidak termasuk dalam kerusakan rusak berat yaitu Gulon. Desa yang paling banyak mengalami kerusakan rusak berat adalah Sirahan 43 rumah, Seloboro 15 rumah, Jumoyo 8 rumah, dan Blongkeng 5 rumah.

Kelas kerusakan tidak rusak bukan berarti rumah yang terdampak banjir lahar tersebut tidak rusak sama sekali, melainkan seperti yang tertera dalam kriteria yaitu bangunan masih berdiri, tak ada kerusakan pada pintu/jendela dan terkena genangan lahar 
kurang dari $20 \mathrm{~cm}$. Kelas kerusakan ini masih didominasi oleh Desa Sirahan yakni 40 rumah, kemudian Jumoyo 24 rumah, dan Seloboro 1 rumah. Desa Gulon dan Desa Blongkeng tidak termasuk dalam kriteria ini. Gambar 8. menjelaskan kerusakan permukiman pada masing-masing kriteria.

\section{Analisis Tingkat Kerusakan Permukiman Akibat Banjir Lahar Di Daerah Penelitian}

Analisis kerusakan permukiman akibat banjir lahar didasarkan pada tinggi endapan banjir lahar dan jarak rumah terhadap sungai. Tinggi endapan banjir lahar adalah 1 hingga $3 \mathrm{~m}$, jarak rumah terhadap sungai berkisar mulai dari $0-250$ meter. Rumah yang terkena endapan banjir lahar setinggi $1 \mathrm{~m}$ mengalami Rusak Ringan, Rusak Sedang dan Roboh/Hanyut. Rumah yang mengalami Rusak Ringan jarak 0 hingga $37 \mathrm{~m}$, terdapat 1 rumah yang berjarak $87 \mathrm{~m}$ dari sungai namun mengalami Rusak Ringan, karena rumah tersebut material dinding dari kayu dan lantai berupa tanah. Rumah yang mengalami Rusak Sedang memiliki jarak terhadap sungai 13 hingga $70 \mathrm{~m}$.

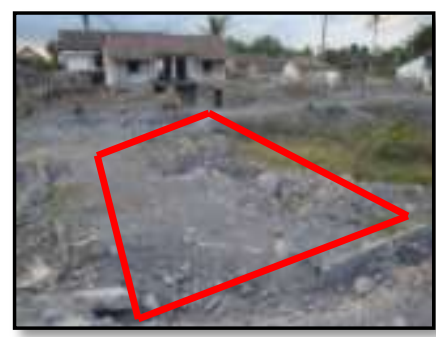

1. Rumah

Roboh/Hanyut, tanda merah menggambarkan bekas rumah

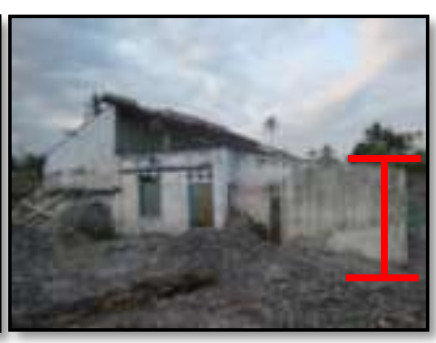

2. Rumah Rusak Berat, tanda merah adalah tinggi banjir lahar

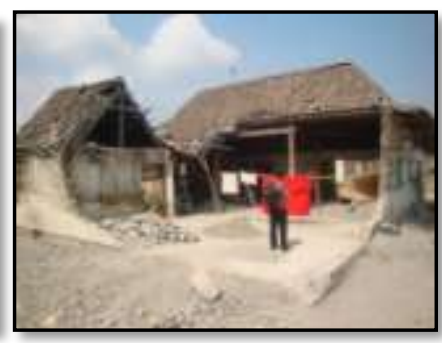

3. Rumah Rusak Sedang

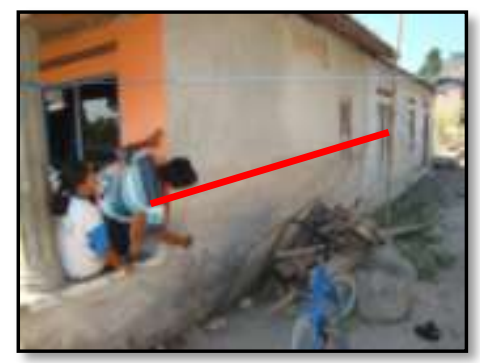

4. Rumah Rusak Ringan, tanda merah adalah batas tinggi banjir lahar

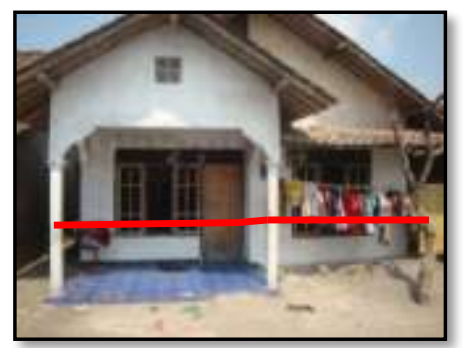

5. Rumah Tidak Rusak tanda merah adalah tinggi banjir lahar

\section{Gambar 8. Kelas Kerusakan Permukiman}

Ketinggian banjir lahar 1,5 m mengakibatkan kerusakan berupa Rusak Ringan, Rusak Sedang, dan Rusak Berat. Rumah yang mengalami rusak ringan, pada jarak $69 \mathrm{~m}$ dari 
sungai, material dinding campuran, batako dan kayu dan berlantai tanah. Rumah yang memiliki jarak dari sungai sejauh $21 \mathrm{~m}$ dan $25 \mathrm{~m}$ mengalami rusak berat, karena dinding rumah terbuat dari kayu dan material lantainya berupa semen. Banjir lahar dengan ketinggian endapan $2 \mathrm{~m}$ mengakibatkan kerusakan berupa Roboh/Hanyut, Rusak Berat, Rusak Sedang, dan bahkan Rusak Ringan. Rumah yang mengalami kerusakan ringan pada endapan banjir lahar setinggi $2 \mathrm{~m}$ berada pada jarak lebih dari $100 \mathrm{~m}$ dari sungai, yaitu rumah- rumah di Desa Gulon.

Ketinggian endapan banjir lahar setinggi $3 \mathrm{~m}$ terjadi di Desa Jumoyo, Seloboro, Sirahan dan Blongkeng. Kerusakan permukiman yang terjadi di Desa Jumoyo, Seloboro, Sirahan dan Blongkeng tidak hanya bergantung pada jarak terhadap sungai dan material bangunan. Hal ini karena, banjir lahar yang melimpas pada keempat desa ini terjadi dengan memotong arus sungai yang sebenarnya, akibatnya rumah yang berada pada jarak lebih dari $200 \mathrm{~m}$ dari sungai pun juga mengalami kerusakan Roboh/Hanyut.

Berdasarkan hasil analisis di atas dapat diketahui bahwa selain jarak terhadap sungai dan ketinggian endapan banjir lahar, kondisi rumah (bahan ,material) juga turut berperan dalam menentukan kerusakan rumah yang terjadi akibat banjir lahar. Kejadian banjir lahar seperti yang terjadi di Kali Putih, banjir lahar melimpas memotong alur sungai yang sebenarnya, maka kerusakan permukiman terparah dimungkinkan dapat terjadi walaupun rumah tersebut berada pada jarak lebih dari $200 \mathrm{~m}$ dari sungai dan material bata, keramik.

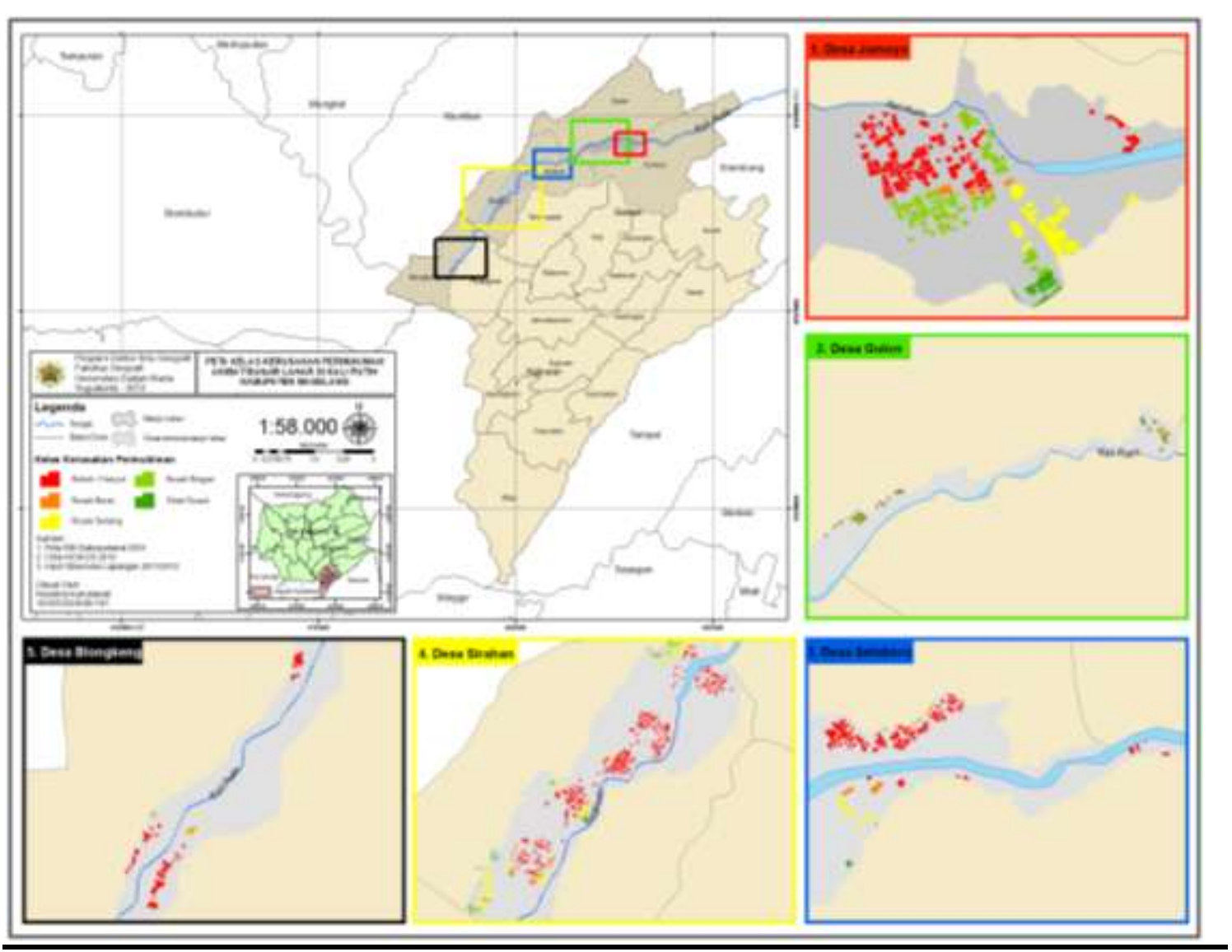

Gambar 9. Peta Kerusakan Permukiman Akibat Banjir Lahar di Kali Putih Kabupaten Magelang Tahun 2012 


\section{Menganalisis Pengalokasian Ruang Pembangunan Pemukiman berbasis Tingkat Kerusakan Permukiman Pasca Banjir Lahar}

Pasca bencana erupsi Gunungapi Merapi (2010) dan bencana banjir lahar khususnya, rencana dan pola pemanfaatan ruang yang relatif aman dari bencana yang sama telah disiapkan pemerintah pusat maupun pemerintah daerah. Pemerintah sedang dalam tahap penyusunan revisi mengenai RTRW Kabupaten Magelang 2010 - 2030 yang tercantum dalam Peraturan daerah (Perda) No 5 Tahun 2011. Rencana-rencana dan pembangunan tata ruang tersebut mengutamakan terjaminnya keterikatan dan konsistensi antara perencanaan, penganggaran, dan pengawasan serta masyarakat berhak terlibat untuk memberikan masukan secara lisan maupun tulisan dalam penyusunan perencanaan pembangunan melalui penjaringan aspirasi dari bawah. Rencana dan pola pemanfaatan ruang pasca bencana di Kabupaten Magelang baik secara makro maupun mikro tetap mengacu kepada kaidah pemanfaatan ruang yaitu pemanfaatan ruang bagi kawasan budaya dan kawasan non budidaya dan ditunjang dengan pemanfaatan ruang mitigasi bencana alam.

Pola pemanfaatan ruang yang terjadi di Kabupaten Magelang, khususnya di sepanjang aliran Kali Putih dapat dilihat berdasarkan berkembangnya kawasan permukiman yang terjadi di beberapa kawasan yang terkena dampak bencana atau mengalami kerusakan fisik. Perkembangan kawasan permukiman dapat dilihat dari peta blok bangunan yang dihasilkan. Daerah dengan kepadatan penduduk paling tinggi menjadi fokus utama dalam perencanaan tata ruang. Terutama kalau daerah tersebut mempunyai kepadatan penduduk tinggi dan terletak pada daerah bahaya. Konsekuensinya apabila perencanaan yang sudah ada tidak segera terlaksana dikarenakan belum selesainya pendataan tata batas persil kepemilikan perorangan, hancurnya kawasan-kawasan budidaya pertanian dan perikanan serta kawasan pariwisata, maka akan mengakibatkan perubahan pemanfaatan lahan yang kurang terkontrol, seperti yang terjadi pada kawasankawasan hunian sementara. Hunian sementara atau huntara di daerah penelitian masih terletak di sekitar daerah bahaya banjir lahar (Gambar 10).
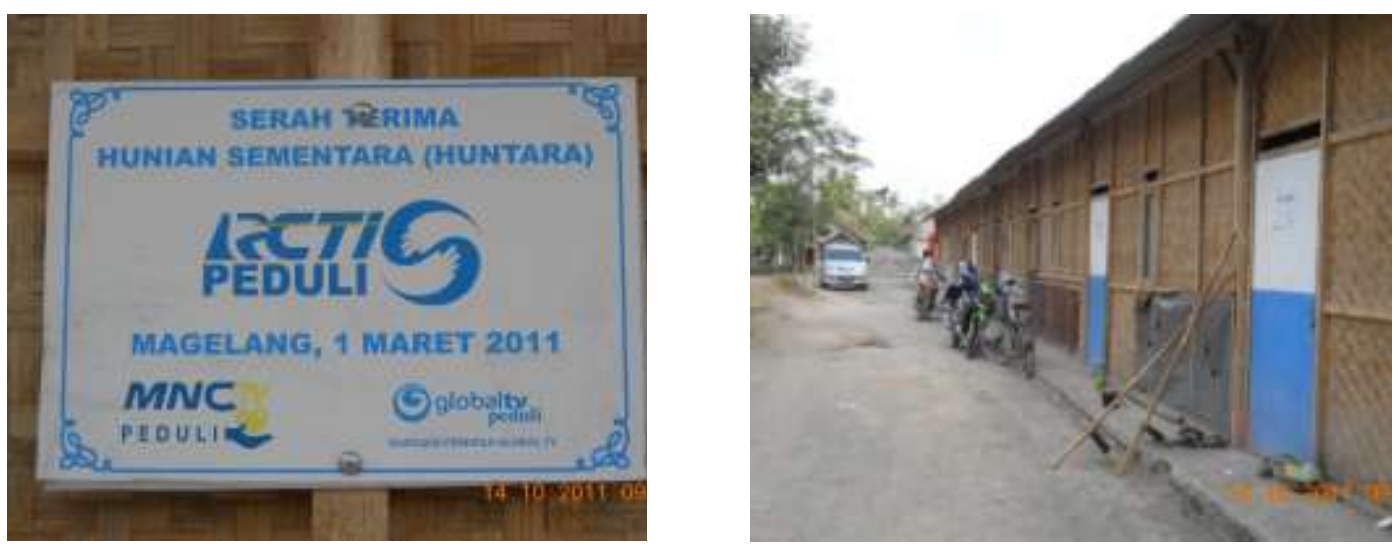

Sumber: Foto Rosalina Kumalawati, dkk, 2012

\section{Gambar 10. Lokasi Huntara (Hunian Sementara) di Daerah Penelitian}

Penataan ruang kawasan bahaya gunungapi dalam hal ini banjir lahar lebih dititikberatkan kepada upaya memelihara dan meningkatkan kualitas ruang melalui upaya peningkatan kelestarian dan keseimbangan lingkungan dengan lebih memperhatikan azas pembangunan berkelanjutan. Pengembangan kawasan permukiman mendapatkan prioritas 
dalam menentukan penggunaan lahan. Pengembangan kawasan permukiman dilakukan untuk mengantisipasi perkembangan penduduk dan menepis kecenderungan pemanfaatan lahan yang hanya memusat pada kantong-kantong permukiman yang telah ada. Akibatnya, wilayah perdesaan sulit berkembang karena jauh dari jangkauan sarana dan prasarana yang memadai. Pasca bencana banjir lahar, sebenarnya perlu dilakukan evaluasi untuk pembangunan permukiman dengan memperhatikan beberapa kriteria antara lain kriteria fisik. Kriteria fisik yang dibutuhkan untuk pembangunan kawasan permukiman adalah:

- Kemiringan antara 0-15\% atau lebih;

- Erodibilitas baik dan bebas banjir atau air genangan.

Berdasarkan peta kerusakan permukiman akibat banjir lahar yang sudah dihasilkan bisa diketahui dimana sebenarnya lokasi paling aman untuk dibangun permukiman. Lokasi yang aman bagi pemukiman, seharusnya memanfaatkan lahan yang sesuai dengan kriteria pemukiman yang aman dan sesuai tata ruang. Dengan mengetahui kondisi penggunaan lahan di daerah penelitian serta peta kerusakan permukiman akibat banjir lahar di daerah penelitian, maka dapat di ketahui arahan pemukiman yang tepat.

Pola pemanfaatan ruang yang ada, sebaiknya mempertimbangkan kemungkinan bencana banjir lahar yang mungkin akan terulang kembali. Sebaiknya pola pemanfaatan ruang juga di dasarkan pada :

- Terbangunnya tata laksana (good governance) yang baik.

- Pengendalian pemanfaatan ruang yang didasarkan kepada aspirasi ataupun berbasis masyarakat dan sinergis dengan kebijakan yang ada,

- Terciptanya mekanisme pengendalian (pengawasan, evaluasi dan penertiban) yang dapat diterapkan pada pemerintah, masyarakat dan stakeholder,

- Dalam pengendalian dan pemanfaatan ruang ini, diharapkan juga masyarakat mengerti akan keterbatasan sumber daya yang ada, baik secara fisik maupun financial pemerintah.

\section{Kesimpulan}

1. Permukiman yang berada di daerah penelitian termasuk dalam kategori rumah permanen, yaitu berpondasi, dinding berupa batu bata/batako, beratap genteng dan memiliki lantai berupa plester/keramik.

2. Tingkat kerusakan permukiman yang berbeda beda tidak hanya diakibatkan oleh jarak rumah terhadap sungai tetapi juga diakibatkan oleh material dinding sebagian rumah yang terdiri dari kayu atau campuran (kayu dan bata/batako).

3. Pengembangan permukiman lebih baik dengan memperhatikan jarak rumah terhadap sungai dan kualitas bahan bangunan agar dapat meminimalisir kerugian akibat banjir lahar.

\section{Ucapan Terima Kasih}

Penelitian ini adalah bagian dari Disertasi yang sedang dikerjakan oleh Rosalina Kumalawati. Ucapan terima kasih dan salam hormat kami sampaikan kepada para pembimbing disertasi yaitu Prof. R. Rijanta selaku promotor, Prof. Junun Sartohadi selaku ko-promotor (keduanya dari Fakultas Geografi UGM) dan Dr. Rimawan Pradiptyo selaku ko-promotor (Fakultas Ekonomika dan Bisnis UGM). Semoga selalu terjalin silaturahim diantara kita. 


\section{Daftar Pustaka}

Badan Nasional Penanggulangan Bencana. 2011. Peta Lokasi Desa Terdampak Banjir Lahar Dingin Gunung Merapi. http://geospasial.bnpb.go.id/. Diakses pada tanggal 8 Februari 2012.

Cholik, Noer. 2011. Ekspedisi Cincin Merapi. Kota Yogya : Balai Penyelidikan dan Pengembangan Teknologi Kegunungapian Daerah Istimewa Yogyakarta.

Departemen Pekerjaan Umum. 2006. Program Rehabilitasi Gempa D.I. Yogyakarta dan Jawa Tengah. http://ciptakarya.pu.go.id/dok/gempa/main.htm. Diakses pada 17 Maret 2012.

Environmental System Research Institute. 2008. ArcGIS Desktop Help. USA : ESRI.

Hadmoko, Danang Sri., Marfai, Muh Aris., Widiyanto. 2011. Pemodelan Mikrozonasi Risiko Bahaya Lahar Akibat Erupsi Merapi 2010 di Wilayah Perkotaan : Kasus Aliran Sungai Code. Laporan Penelitian. Yogyakarta : Fakultas Geografi UGM.

Kumalawati, Rosalina., Permatasari, Afrinia Lisditya., Rijal, Seftiawan S. 2012. Pengelolaan Daerah Bahaya Lahar Pasca Erupsi Gunungapi Merapi 2010 di Kali Putih Kabupaten Magelang, Jawa Tengah. Prosiding Seminar Nasional PJ dan SIG 2012 UMS. Surakarta : Fakultas Geografi UMS.

Kumalawati, Rosalina. Rijal, Seftiawan Samsu. Rijanta. Sartohadi, Junun. Pradiptyo, Rimawan Pradiptyo. 2012. The Mapping of Lahar Flood Risk About Residential In Salam Sub-District, Magelang, Central Java. Proceeding The 2nd ACIKITA International Conference. Jakarta : ACIKITA Publishing.

Kumalawati, Rosalina. Rijal, Seftiawan Samsu. Rijanta. Sartohadi, Junun. Pradiptyo, Rimawan Pradiptyo. 2012. The Evaluation of Residential Development Based on Lahar Risk Analysis in Kali Putih Sub-watershed, Magelang, Central Java, Indonesia. Proceeding The 2nd ACIKITA International Conference. Jakarta : ACIKITA Publishing.

Kumalawati, Rosalina. Rijal, Seftiawan Samsu. Rijanta. Sartohadi, Junun. Pradiptyo, Rimawan Pradiptyo. 2012. Pemetaan Tingkat Kerawanan Banjir Lahar Untuk Evaluasi Pengembangan Permukiman Berdasarkan Batas Dusun Di Kecamatan Salam, Magelang, Jawa Tengah. Prosiding Seminar Nasional Menuju Masyarakat Madani dan Lestari. Yogyakarta : DPPM UII.

Kusumowidagdo, Mulyadi., Sanjoto, Tjaturahno Budi., Banowati, Eva., Setyowati, Dewi Liesnoor., Semedi, Bambang. 2007. Penginderaan Jauh dan Interpretasi Citra : Buku Pengantar Penginderaan Jauh. Jakarta : Lembaga Penerbangan dan Antariksa Nasional.

Lavigne, F., Thouret, J. C., Voight, B., Suwa, H., Sumaryono, A. 2000. Lahars at Merapi Volcano : an Overview. Journal of Volcanology and Geothermal Research Volume 100. Hal : $421-456$.

Lavigne, Franck. 1999. Lahar Hazard Micro-Zonation and Risk Assessment in Yogyakarta City, Indonesia. GeoJournal Volume 49. Hal : 173 - 183.

Mustafa, Hasan. 2000. Teknik Sampling. home.unpar.ac.id/ hasan/SAMPLING. Diakses pada 1 Maret 2012.

Rijal, Seftiawan Samsu. 2012. Analisis Kerusakan Permukiman Akibat Banjir Lahar Pasca Erupsi Gunungapi Merapi 2010 di Sebagian Kabupaten Magelang. Skripsi. Surakarta : Fakultas Geografi UMS.

Silitonga, Petra Silas. 2010. Definisi Perumahan dan Rumah. Diakses 1 Oktober 2012.

Sumintadireja, Prihadi. 2000. Catatan Kuliah Volkanologi. Bandung : ITB.

Tobler, Wado R. 1987. Kesepadanan Skala Peta dan Resolusi Citra. http://lajugandharum.wordpress.com. Diakses pada 4 April 2012.

Yunus, Hadi Sabari. 2010. Metodologi Penelitian Wilayah Kontemporer. Yogyakarta : Pustaka Pelajar. 